\title{
Social Security Systems, Human Capital, and Growth in a Small Open Economy
}

\author{
MichaEL KAGANOVICH \\ VOLKER MEIER
}

CESIFO WORKING PAPER NO. 2488

CATEGORY 1: PubliC FinANCE

DECEMBER 2008
An electronic version of the paper may be downloaded
- from the SSRN website: Www.SSRN.com
- from the RePEc website: $\quad$ www.RePEc.org
- from the CESifo website: www.CESifo-group.org/wp




\title{
Social Security Systems, Human Capital, and Growth in a Small Open Economy
}

\begin{abstract}
We consider a small open economy in which the level of public education funding is determined by popular vote. We show that growth can be enhanced by the introduction of pay-as-you-go pensions even if the growth rate of aggregate wages falls short of the interest rate. The reason is that the PAYG system allows future retirees to partially internalize positive externalities of public education due to the positive effect of higher future labor productivity on their pension benefits. The majority support for education funding will be especially strong when the PAYG benefit formula is flat, i.e. progressively redistributive. This means that if a flat benefit PAYG pension system is in place then the economy will achieve the highest growth rate relative to the alternative pension system designs. We argue furthermore that while such PAYG pension system may be opposed by the majority of working individuals due to inferior returns to their pension contributions relative to a funded scheme, it is likely to be politically sustained by the coalition of retirees and lower income workers.
\end{abstract}

JEL Code: D90, H23, H55, I28.

Keywords: pay-as-you-go pensions, social security, public education, growth, majority voting.

\author{
Michael Kaganovich \\ Department of Economics \\ Indiana University \\ Wylie Hall \\ Bloomington, IN 47405 \\ USA \\ mkaganov@indiana.edu
}

\author{
Volker Meier \\ Ifo Institute for Economic Research and \\ CESifo at the University of Munich \\ Poschingerstrasse 5 \\ 81679 Munich \\ Germany \\ meier@ifo.de
}

November 2008

We gratefully acknowledge financial support by CAEPR at Indiana University, CESifo, and the Stifterverband fuer die deutsche Wissenschaft. 


\section{Introduction}

Public pay-as-you-go (PAYG) pension schemes in which pensions are financed by contributions from current workers have often been criticized as detrimental to growth. According to Feldstein (1974) such pension schemes have a negative effect on capital accumulation since they discourage private saving and, unlike in the case of a funded pension system, the payments into the PAYG scheme do not contrib ute to the national saving. Moreover, the implicit rate of return on contributions to a PAYG scheme typically falls short of the interest rate. Therefore according to such analysis, PAYG pension systems reduce per capita income.

This standard argument is focused on physical capital accumulation and fails to take notice of the effect of PAYG pension systems have on the accumulation of human capital, particularly through public education. Primary and secondary education is now overwhelmingly publicly financed in all OECD countries, and universities also receive substantial funding from public sources. Since PAYG pension schemes typically tie pension benefits of future retirees to the productivity of their contemporary workers, they create an incentive to support greater investment in the human capital of those future workers. Therefore if a PAYG pension scheme is introduced, its future beneficiaries may become supportive of higher funding of public education via taxes since they will take into account the positive impact of aggregate human capital accumulation on their pensions. The resulting wage income growth may more than offset losses to economic growth due to the negative effect on physical capital accumulation. This seems particularly likely in a world of integrated capital markets, where international capital flows substantially reduce the impact of national saving on factor prices and the supply of capital. In fact, both the size of public PAYG pension schemes and the share of expenditure on public education in GDP have grown substantially over the first decades after the Second World War in almost all OECD countries. This paper provides a possible explanation for this co-movement and offers a model representing an intergenerational compact where a PAYG system supported by retirees compels the working generation, i.e. the future retirees, to support greater funding of public education, consistent with the analysis by Becker and Murphy (1988).

To illustrate the potentially beneficial impact of a PAYG scheme in its simplest form, we analyze a small open economy in which savings do not affect the interest rate or the supply of capital. We argue that wage income growth in such an economy will generally be stronger under PAYG pension schemes, in comparison to the fully funded pension 
systems. This can be true even if the return on PAYG contributions is below the interest rate.

The concept that PAYG schemes provide an incentive for investing in public education has already been noted by Pogue and Sgontz (1977) as well as Becker and Murphy (1988) who also pointed out that this incentive is stronger for the middle and lower income populations. This concept has become a common feature in the analysis of intergenerational transfers in various contexts (Konrad, 1995; Kaganovich and Zilcha, 1999; Kemnitz, 2000; Boldrin, 2005; Poutvaara, 2006; Soares, 2006). For the environments in which parents finance the education of their children, including those where private and public channels coexist, it has been argued that positive growth effects of introducing a PAYG scheme can be expected because it helps relax parents' liquidity constraints: see Kaganovich and Zilcha (1999), Lambrecht et al. (2005), Glomm and Kaganovich (2008). ${ }^{2}$ The latter paper which focuses on the role of income heterogeneity underscores the point that the effect of relaxing liquidity constraint on educating children is particularly strong in lower income families when PAYG pension benefits are redistributive.

Another strand of the literature is concerned with normative aspects of linking public education and PAYG schemes. One efficiency argument for providing schooling publicly lies in the impossibility to enforce transfer payments by children in exchange for financing education within the family (Sinn, 2004). But if altruism toward the young is weak, the level of public education may be chosen where the marginal return to investment in human capital exceeds the interest rate. In such a situation, PAYG pensions will enhance efficiency by fostering human capital accumulation. Rangel (2003) studies an intergenerational contract with public education and PAYG pensions aimed at restoring efficiency. Boldrin and Montes (2005) argue that these two parts of government intervention can be used to replace the missing market for financing investment in human capital in an efficient fashion. Our paper can be seen as complementing this literature by pursuing a positive approach. It argues that the possible efficiency gains of increased education funding will be at least partly realized in a political economy framework.

\footnotetext{
${ }^{2}$ Pecchenino and Utendorf (1999) reach an opposite conclusion for a model where education is exclusively privately funded: PAYG social security will depress investment in both physical and human capital. This is so due to the negative income effect of social security payroll tax, under the assumption that the returns on social security contributions are inferior to returns on private savings for all individuals. It is important to observe, in particular, that when education is funded only privately by parents, they fail to internalize the impact of children's education on the aggregate productivity of future workers and through it on the magnitude on the future PAYG retirement benefits.
} 
The contributions most closely related to ours are those by Kaganovich and Zilcha (2008) and Soares (2006). The former analyzes a closed economy setting where, similar to Boldrin (2005), voters take into account positive externalities of human capital accumulation for the future return on savings and pension contributions. It turns out that negative growth effects of introducing a PAYG scheme due to reduced physical capital accumulation will generally outweigh, in a fully closed economy, the positive growth effects of the enhanced human capital accumulation. Our present paper shows that these results may be turned around when one allows for international mobility of capital, such that the positive human capital effect dominates. Indeed, Soares (2006) notes that education tax rates tend to be higher in an open economy, for a calibrated model with a differentiated age structure, a mixed education system with public and private schooling, and labor-leisure choice. By considering a simpler framework, we are able to generalize his results, to demonstrate the existence of exceptions to this conclusion, to address the effects of alternative pension benefit formulas on education funding and growth and to characterize the implications for the choice of the pension scheme.

In our comparative analysis of growth implications of PAYG and fully funded pension systems we further distinguish between contribution-related and redistributive pension formulas which affect individuals differently depending on their position in the distribution of income. When the level of public education funding is politically determined and the income of the median voter falls short of the mean income, then his children are subsidized through public education. Under certain conditions this implies that lower income voters exhibit stronger support for education funding. On top of that, the median voter may benefit through a public pension scheme if it is also redistributive, e.g. flat. We show that this subsidization effect of a flat pension formula can elicit majority political support for a relatively higher level of public education funding. ${ }^{3}$

We note that the growth implications of contribution-related vs. flat pension benefit formulae depend starkly on the tax structure. If education is financed by a payroll tax, then the median voter tends to be a worker earning below average wage. However, if education is funded via an income tax or a consumption tax, then a part of tax liability falls on the retirees who have little or no incentive to support education funding; there-

\footnotetext{
${ }^{3}$ This contrasts the conclusions in the literature dealing with growth impacts of pension systems when education is privately funded, which argues that contribution-related pension formulas, rather than those with flat benefits, particularly encourage human capital formation and growth (Kemnitz and Wigger, 2000; Docquier and Paddison, 2003).
} 
fore the median voter in this situation is likely to be among the above average wage earners. Consequently, the median voter would tend to be harmed by a redistributive benefit formula in a pension scheme, and would therefore support lower level of public education funding than under the corresponding contribution-related pensions. Our view that the elderly have a particularly low preference to finance public education is in line both with the empirical evidence (Poterba, 1997 and 1998) and theoretical studies (Gradstein and Kaganovich, 2004; Holtz-Eakin et al., 2004; Poutvaara, 2006).

Thus our paper provides an analysis of inter- and intra-generational redistributional effects of alternative pension schemes when education is publicly funded, and of their implications for political support for education funding and growth. One of our main results (Theorem 2), obtained under conditions characteristic of most developed economies, is that a PAYG pension system with redistributive benefit formula yields the highest growth rate relative to the alternative pension system designs. Furthermore, we argue (Theorem 3 and the Corollary) that while such PAYG pension system may be opposed by the majority of working individuals due to its inferior returns on their pension contributions relative to a funded scheme, it is likely to be politically sustained by the coalition of retirees and lower income workers. Once in place, the PAYG system compels a majority of working individuals to support higher public funding of education, and hence enhances economic growth.

The remainder of our paper is organized as follows. After introducing the model in Section 2, we investigate the impact of different benefit formulas within a given pension scheme on education funding and growth in Section 3. We build on this analysis in Section 4 to obtain our main results comparing the implication of funded and PAYG schemes for education funding and growth. In Section 5, we consider individual rates of return to social security contributions arising in different pension schemes and the ir implication for preferences for and political sustainability of a pension scheme. The final Section 6 summarizes and discusses our findings.

\section{The basic model}

We consider an overlapping generations small open economy where perfectly competitive firms produce a homogeneous good using human and physical capital as inputs in a constant returns neoclassical technology. Physical capital is internationally mobile and therefore the interest factor is exogenous from the vantage point of the small open economy. For simplicity but without essential loss of generality we postulate the interest 
factor $R$ to be stationary. The constant returns technology then implies that the wage rate $w$ per efficiency unit of labor (human capital) is also exogenous and stationary.

Each individual in this OLG population lives for three periods: childhood, working age, and retirement. An individual is ndexed by his family name $\omega$ and his generation $\mathrm{t}=0,1,2, \ldots$ which is identified with the time period of his working age. At the beginning of his working age each individual gives birth to an exogenously set number $\mathrm{n}$ of children, who will bear his family name. By $\Omega_{t}$ we denote the set encompassing the population of generation $\mathrm{t}$ individuals and we let $\mu_{t}(\omega)$ be the Lebesgue measure on $\Omega_{t}$ which we assume is well defined.

Human capital endowments $h_{0}(\omega)$ of the members of the initial generation 0 are presumed given. As a child, i.e. during the time period $\mathrm{t}-1$, each member of ge neration $\mathrm{t}=1,2, \ldots$ receives public education in a uniform amount $e_{t-1}$ which is funded by a proportional education tax on contemporary wage income whose rate is determined by the parents generation through a political process. The human capital is attained by the start of one's working age according to the education production function

$$
h_{t}(\omega)=B\left[h_{t-1}(\omega)\right]^{\sigma} e_{t-1}^{1-\sigma},
$$

with $B>0$ and $0<\sigma<1$, where $h_{t-1}(\omega)$ is the parent's human capital, thus both school and family inputs contribute to a child's human capital accumulation. Note that all individuals in generation $\mathrm{t}$ who share a family name $\omega$ are identical in their human capital attainment. Wherever possible without loss of clarity we'll be omitting family identification $\omega$ for brevity.

During his working age, an individual inelastically supplies his human capital and receives wage income

$$
I_{t}(\omega)=w h_{t}(\omega)
$$

He is required to contribute a fixed fraction $\tau$ of his wage income to the public pension scheme, and also pays a payroll tax at a rate ${ }_{t}$ to finance public public education system. He allocates his disposable income to working age consumption $c_{t}^{y}(\omega)$ and savings $s_{t}(\omega)$ such that 


$$
c_{t}^{y}(\omega)=\left(1-\tau-\theta_{t}\right) w h_{t}(\omega)-s_{t}(\omega)
$$

In his the old age, the generation $t$ individual consumes his entire assets equal to the sum of his public pension $\pi_{t+1}(\omega)$ and the gross return on savings. Thus his old-age consumption is given by

$$
c_{t}^{o}(\omega)=\pi_{t+1}(\omega)+R s_{t}(\omega)
$$

Preferences are defined by a utility function $U\left(c_{t}^{y}, c_{t}^{o}, h_{t+1}\right)$ that is strictly increasing and strictly concave in all arguments, where the third argument is the level of human capital attained by the children of the individual, which reflects parental altruis $m$. For analytical tractability we will consider the case of additively-separable logarithmic utility:

$$
U\left(c_{t}^{y}, c_{t}^{o}, h_{t+1}\right)=\alpha \ln c_{t}^{y}+\beta \ln c_{t}^{o}+\gamma \ln h_{t+1}
$$

with $\alpha, \beta, \gamma>0$.

According to the first-order condition of the individual optimization problem (2)-(4), the optimal levels of saving, young-age and old-age consumption are given by, respectively:

$$
\begin{aligned}
& s_{t}(\omega)=\frac{\beta}{\alpha+\beta}\left(1-\tau-\theta_{t}\right) I_{t}(\omega)-\frac{\alpha \pi_{t+1}(\omega)}{(\alpha+\beta) R} \\
& c_{t}^{y}(\omega)=\frac{\alpha}{\alpha+\beta}\left[\left(1-\tau-\theta_{t}\right) I_{t}(\omega)+\frac{\pi_{t+1}(\omega)}{R}\right] \\
& c_{t}^{o}(\omega)=\frac{R \beta}{\alpha+\beta}\left[\left(1-\tau-\theta_{t}\right) I_{t}(\omega)+\frac{\pi_{t+1}(\omega)}{R}\right]
\end{aligned}
$$

Since we assume that expenditures on education are financed by a proportional payroll tax, the school budget equation is given by

$$
n e_{t}=\theta_{t} \bar{I}_{t}=\theta_{t} w \bar{h}_{t}
$$


where $\bar{I}_{t}$ and $\bar{h}_{t}$ are, respectively, the average individual wage income and the average individual human capital level in the generation t. According to the notation introduced earlier

$$
\bar{h}_{t}=\frac{\int_{\Omega_{t}} h_{t}(\omega) d \mu_{t}(\omega)}{\mu_{t}\left(\Omega_{t}\right)}
$$

whereby we note that according to the exogenous population dynamics defined above $\mu_{t+1}\left(\Omega_{t+1}\right)=n \mu_{t}\left(\Omega_{t}\right)$.

Combining the expressions (7) and (1) yields the expression for the dynamics of ind $\mathrm{i}-$ vidual human capital:

$$
h_{t+1}(\omega)=B\left[h_{t}(\omega)\right]^{\sigma} \theta_{t}^{1-\sigma}(w / n)^{1-\sigma} \bar{h}_{t}^{1-\sigma}
$$

Then using (8) we obtain the equation for the dynamics of the average human capital

$$
\bar{h}_{t+1}=\bar{h}_{t} B\left[\frac{\theta_{t} w}{n}\right]^{1-\sigma} M_{t} \quad \text { where } M_{t}=\left[\mu_{t}\left(\Omega_{t}\right)\right]^{-1} \int_{\Omega_{t}}\left[\frac{h_{t}(\omega)}{\bar{h}_{t}}\right]^{\sigma} d \mu_{t}(\omega)
$$

Note that the expression $M_{t}$ in equation (10) characterizes the dispersion of human capital (equivalently, of wage income) in the population. Its highest value is 1 , which obtains iff human capital attainment is completely homogeneous; $M_{t}$ declines with increasing dispersion of incomes. Thus equation (10) implies that given the same education funding levels the average human capital will grow at the higher rate across generations the less dispersed are the wage incomes.

We assume that period $\mathrm{t}$ education tax rate $\theta_{t}$ is determined by majority voting. In our model the current old do not bear the cost nor receive the benefit of education spending in period t. Therefore they are assumed to be indifferent to the vote's outcome and to abstain in the vote. We will discuss the implications of the model's modifications where the elderly participate in the vote, at the end of Section 3.

We will present a comparative analysis of pay-as-you-go (PG) and fully funded (FF) public pension schemes, where each can use either a contribution-related or a flat pen- 
sion formula. We will use the self explanatory superscripts $P G c, P G f, F F c$, and $F F f$ in the notation associated with the respective pension systems. The pension benefits provided under the respective schemes are given by

$$
\begin{aligned}
& \pi_{t+1}^{F F c}(\omega)=R \tau I_{t}(\omega)=R \tau w h_{t}(\omega) \\
& \pi_{t+1}^{F F f}=R \tau \bar{I}_{t}=R \tau w \bar{h}_{t} \\
& \pi_{t+1}^{P G c}(\omega)=n \tau \bar{I}_{t+1}\left(I_{t}(\omega) / \bar{I}_{t}\right)=n \tau w \bar{h}_{t+1}\left(h_{t}(\omega) / \bar{h}_{t}\right) \\
& \pi_{t+1}^{P G f}=n \tau \bar{I}_{t+1}=n \tau w \bar{h}_{t+1}
\end{aligned}
$$

Thus under the fully funded schemes pension benefits are financed by the returns on the investment of the beneficiaries' contributions. While the flat version of the scheme is intra-generationally redistributive, the contribution related scheme is equivalent to the private saving, albeit at a prescribed rate. The pay-as-you-go schemes, however, constitute an inter-generational transfer where the benefits to the retirees are funded by taxes on the wage income of the contemporary workers. Thus the effective returns to one's contributions into the system are directly tied to wage growth, i.e. to the growth of labor productivity in the next generation of workers.

Since the factor prices are exogenous and stationary, physical capital is perfectly mobile and the neoclassical technology exhibits constant returns to scale, the supply of human capital and the dynamic competitive equilibrium are uniquely determined, for a given sequence of education tax rates $\theta_{t}$ and a specified pension scheme, by the allocation decisions of individual agents as expressed by the relationships in (6).

As stated above, in each period $\mathrm{t}$ education tax rate $\theta_{t}$ is determined by majority voting of the relevant constituents, i.e. the members of generation t. In the next section, we will derive the most preferred levels of the tax for individual members of the generation based on their preferences and resource allocations in the dynamic competitive equilibrium. We will also show that this allows one to uniquely and recursively define the tax rate chosen by the majority in each period. We define the recursive dynamic political equilibrium (DPE) as the resulting sequence of education tax rates $\left\{\theta_{t}\right\}_{t=0,1, \ldots}$ combined with the corresponding dynamic competitive equilibrium. 
In our comparative dynamics experiment we compare the economic outcomes in respective dynamic political equilibria under alternative social security schemes, characterized by benefit formulae (11a) - (11d), introduced in period $t=0$. In cases of a PG scheme this means that the generation of retirees present at $\mathrm{t}=0$ receives the benefits as an unticipated gift which therefore has no effect on their young-age political and saving decisions.

\section{Intra-generational redistribution in pension benefit formulas and growth}

In this Section, we will compare the effect that the choice of flat vs. contribution related benefit formula has on growth under either pay-as-you-go or fully funded systems. When the pension benefit brmula is flat it is progressively redistributive within each generation of retirees, as opposed to the contribution related pension benefit formula. We will therefore show how these pension formulas differ in their impact on incentives of different income groups to support funding of public education, via the choice of the education tax rate, and thereby on growth.

We will first show that individual preferences are single-peaked with respect to the education tax rate. Substituting the consumption functions given in (6) as well as the expressions (1) and (7) for the human capital production into the utility function (5) we obtain the expression for the working age individual's value function

$$
U_{t}^{*}(\omega, \theta)=(\alpha+\beta) \ln \left[(1-\tau-\theta) I_{t}(\omega)+\frac{\pi_{t+1}(\omega)}{R}\right]+\gamma(1-\sigma) \ln \theta+D
$$

where $D$ summarizes the terms that do not depend on $\theta$.

Lemma 1: The value function is strictly concave in $\theta$ under either of the pension formulae (11a)-(11d).

Proof. See the Appendix.

According to Lemma 1 each individual has a unique most preferred education tax. Using the first order condition of maximum of the function $U^{*}(\theta)$ defined in (12) as well 
as the relationship (7), we obtain the expression for the tax rate preferred by generation $\mathrm{t}$ individual in family $\omega$ :

$$
\theta_{t}^{*}(\omega)=\frac{\gamma(1-\sigma)\left[1-\tau+\frac{\pi_{t+1}(\omega)}{R I_{t}(\omega)}\right]+(\alpha+\beta) \frac{e_{t}}{R I_{t}(\omega)} \frac{\partial \pi_{t+1}(\omega)}{\partial e_{t}}}{\alpha+\beta+\gamma(1-\sigma)}
$$

where the term $e_{t} \frac{\partial \pi_{t+1}(\omega)}{\partial e_{t}}$ in general depends on the value of $\theta_{t}^{*}(\omega)$

Under the contribution-related fully funded pension scheme, according to (13) and the benefit formula (11a), the choice of the DPE education tax rate is unanimous and constant over time:

$$
\theta_{t}^{F F c} \equiv \theta^{F F c}=\frac{\gamma(1-\sigma)}{\alpha+\beta+\gamma(1-\sigma)}
$$

Note that since this particular pension scheme is equivalent to a self-financed retirement, the preferred education tax rate given by (14a) is motivated purely by each individual's altruistic concern for the educational attainment of his children in the public school system. The unanimity of the preferred tax rate is a consequence of the logarithmic specification of the utility function. Replacing it by a more general CES form would make the preferred tax rates decrease or increase in individual's income, depending on the elasticity of substitution between own consumption and children's education. Empirical estimates of income and substitution elasticities suggest that the logarithmic (equivalently, Cobb-Douglas) specification of the utility function is a reasonable approximation (Gradstein et al., 2005, ch. 4), implying that the preferred education tax should indeed vary little across incomes under the contribution related fully funded pension system in the framework at hand.

If a funded scheme uses the flat benefit formula (11b), then the logarithmic utility implies that the preferred tax rate falls with increasing wage income. Indeed, according to (11b) pension benefits do not depend on future workers' human capital, i.e. $\frac{\partial \pi_{t+1}(\omega)}{\partial e_{t}}=0$ and therefore according to (13) 


$$
\theta_{t}^{F F f}(\omega)=\frac{\gamma(1-\sigma)\left[1-\tau+\tau \frac{\bar{h}_{t}}{h_{t}(\omega)}\right]}{\alpha+\beta+\gamma(1-\sigma)}
$$

Thus under this flat pension benefit scheme, similarly to the contribution related case described by (14a), all individuals prefer to devote the same, altruistically motivated fraction of lifetime income to public education. However, given the redistributive nature of the flat scheme this implies that the preferred rate of education tax decreases in individuals' wage income.

Let $\theta_{t}^{F F f}\left(\bar{I}_{t}\right)$ stand for the tax rate preferred by generation $\mathrm{t}$ individuals whose wage equals to the economy's average. Then according to (14b) and (14a) $\theta_{t}^{F F f}\left(\bar{I}_{t}\right)=\theta^{F F c}$. Furthermore, assuming that the median voter earns less than the average wage, a majority of workers under the flat benefit fully funded pension scheme will prefer a higher education tax rate than the rate $\theta^{F F c}$ chosen under the contribution-related fully funded pension system. Likewise, if the median voter earns an above average wage, then a majority of workers under the $F F f$ system will prefer a lower education tax rate than $\theta^{F F c}$.

The following Proposition summarizes the above argument and shows furthermore that a similar comparative result holds for the contribution related vs. flat PAYG pension schemes.

Proposition 1: (i) Assume that median voter's wage income is below the average. Then for a given pension contribution rate $t$ and the pension scheme type (funded or PAYG) the DPE education tax rate $\theta_{t}$ in each period $t$ will be higher under a flat pension benefit formula than under the corresponding contribution-related one. In other words, the following inequalities are true:

$$
\theta_{t}^{F F f}>\theta^{F F c} \text { and } \theta_{t}^{\text {PGf }}>\theta_{t}^{\text {PGc }} \text { for all } t=0,1, \ldots
$$

(ii) Assume that median voter's wage income is above the average. Then for a given pension contribution rate $t$ the respective comparisons yield the results opposite to those in part (i), i.e. the following inequalities are true:

$$
\theta_{t}^{F F f}<\theta^{F F c} \text { and } \theta_{t}^{P G f}<\theta_{t}^{P G c} \text { for all } t=0,1, \ldots
$$

Proof. As argued above, the proof for the case of fully funded pensions is established by comparing the expressions (14a) and (14b). We will now turn to the case of pay-as- 
you-go pensions. Under the contribution-related PG pension scheme, the chosen education tax rate is independent of income. Indeed, according to relationships (11c) and (12) it satisfies

$$
\theta_{t}^{P G c}=\frac{\gamma(1-\sigma)\left[1-\tau+\tau \frac{n}{R} \frac{\bar{h}_{t+1}}{\bar{h}_{t}}\right]+(\alpha+\beta) \tau(1-\sigma) \frac{n}{R} \frac{\bar{h}_{t+1}}{\bar{h}_{t}}}{\alpha+\beta+\gamma(1-\sigma)}
$$

Likewise, according to (11d), under the flat benefit PG pension scheme the individual preferred education tax rates satisfy the equation

$$
\theta_{t}^{P G f}(\omega)=\frac{\gamma(1-\sigma)\left[1-\tau+\tau \frac{n}{R} \frac{\bar{h}_{t+1}}{h_{t}(\omega)}\right]+(\alpha+\beta) \tau(1-\sigma) \frac{n}{R} \frac{\bar{h}_{t+1}}{h_{t}(\omega)}}{\alpha+\beta+\gamma(1-\sigma)}
$$

We note that $\bar{h}_{t+1}$ on the right-hand sides of (14c) and (14d) depends on the education tax rates. Lemma 1 implies that (14c) defines a unique unanimously most preferred education tax rate under contribution-related pensions, and that $(14 \mathrm{~d})$ has a unique individual-specific solution $\theta_{t}^{P G f}(\omega)$. Comparing (14c) to (14d) immediately shows that $\theta_{t}^{P G f}\left(\bar{I}_{t}\right)=\theta_{t}^{P G c}$ where $\theta_{t}^{P G f}\left(\bar{I}_{t}\right)$ is the education tax rate preferred, under the corresponding pension scheme, by generation $t$ individuals whose wage equals to the economy's average. Moreover, it is obvious from (14d) that the preferred rate of education $\operatorname{tax} \theta_{t}^{P G f}(\omega)$ decreases in individuals' wage income, which implies the Proposition's results for the cases of pay-as-you-go pension systems. I

It is clear that the choice of a higher education tax rate will result, ceteris paribus, in speedier accumulation of human capital. In the case of a small open economy at hand, moreover, it also implies a faster economic growth. Indeed, due to perfect capital mobility, neoclassical constant returns technology and the assumed stationarity of the interest rate, physical capital will be supplied in constant proportion to the human capital, and thereby the aggregate output will grow at the rate of human capital accumulation. Let $g_{t}$ denote the growth factor of per capita output, then as explained above it is equal to the growth factor of the average human capital. Therefore according to (10) 


$$
g_{t}=\frac{\bar{h}_{t+1}}{\bar{h}_{t}}=B \theta_{t}^{1-\sigma}\left[\frac{w}{n}\right]^{1-\sigma} M_{t}
$$

Let $g_{t}^{F F c}, g_{t}^{F F f}, g_{t}^{P G c}, g_{t}^{P G f}$ denote the respective per capita growth factors which obtain in the dynamic political equilibria under the pension schemes defined by the benefit formulae (9a)-(9d). The relationship (13) along with Proposition 1 leads to the following result showing that in a small open economy a social security scheme which generates greater support for public education funding will also yield relatively speedier economic growth at all times $\mathrm{t}=0,1, \ldots$.

Theorem 1: (i) Assume that median voter's wage income is below the average. Then under the provisions of Proposition 1 the economy's growth rate will be higher in each period under a flat, i.e. redistributive among retirees, pension benefit formula (whether $P A Y G$ or FF) than under the corresponding contribution-related one. In other words, the following inequalities are true:

$$
g_{t}^{F F f}>g_{t}^{F F c} \text { and } g_{t}^{P G f}>g_{t}^{P G c} \text { for all } t=0,1, \ldots
$$

(ii) Assume that median voter's wage income is above the average. Then under the provisions of Proposition 1 the respective comparisons yield the results opposite to those in part (i), i.e. contribution related pension benefit formulas are more conducive to economic growth. In other words, the following inequalities are true:

$$
g_{t}^{F F f}<g_{t}^{F F c} \text { and } g_{t}^{P G f}<g_{t}^{P G c} \text { for all } t=0,1, \ldots
$$

Proof. Observe that according to the relationships (9) and (10) the expression $M_{t}$ in equation (15) is invariant of the pension scheme and of the education tax rate $\theta_{t}$. Therefore the choice of a pension scheme affects growth factor $g_{t}$ only directly through the term $\theta_{t}^{1-\sigma}$ in equation (15), which is determined by the DPE value of the education tax rate corresponding to each of pension systems. Thus it remains to refer to Proposition 1.1

The intuition for the above results is given by the fact that when the pension contribution rate is fixed and the pension benefit formula is flat, it progressively redistributes retirement income within each generation, as opposed to the case of contribution related pension benefits. If the pension scheme is fully funded, this means that poorer agents will be willing to devote relatively higher fraction of their income to education funding 
based on the uniform degree of altruistic motive. Under a PAYG pension scheme, the individual rate of return it offers on investment in public education of the next generation's workers is likewise higher for the agents with below average income who will therefore support relatively higher levels of education funding. Thus, for a given pension scheme (PAYG or funded) and a given wage income distribution in which mean income exceeds median income (so below average wage earners are in the majority) the wage growth will be faster under the flat benefit pension formula, as stated in Proposition 1(i) and Theorem 1(i).

These results are reversed when the median voter earns more than the average wage. In such a situation, moving from a contribution-related pension scheme to a flat benefit scheme of the same type at a given contribution rate reduces public investment in education and growth. Such a situation may easily occur although empirical wage distributions always exhibit median below the mean. When education is funded, in addition to taxes on wages also through taxes on non-wage income and/or consumption, the elderly are no longer indifferent with respect to the choice of the tax level. Since they will not benefit from workers' productivity in the next period, and since they (in our model) do not have an operative altruistic motive, unlike the young parents, their preferred tax rate is zero. Ordering the individuals by the level of preferred tax rates will then typically show that a median voter will be a working age individual with above average wage income, even if the wage distribution is skewed right. The current trends in life expectancy and fertility in OECD countries indeed point in the direction of a scenario with the median voter earning more than the average wage. Since the tax burden of the old is generally not negligible, one may expect that growth effects of a given pension scheme will be less favorable under Beveridgean-style flat benefits.

\section{Funded vs. PAYG pensions}

While the previous Section focused on the growth effect of intra-generational redistribution in a pension benefit formula, we will now turn to the impact of intergenerational transfers. Namely, we will compare the growth outcomes under the PAYG system, which transfers pension benefits from the young to the old, to the growth outcomes under the fully funded (FF) system which is financed by the retirees themselves.

We will first compare the dynamic political equilibrium education tax rates obtained under the PAYG and FF. Using the expression (12) for the value function of an individual as well as the pension benefit formulae (11c) and (11d), we obtain the value function 
expressions for the cases of contribution related and flat benefit PAYG systems, respectively:

$$
\begin{aligned}
& U_{t}^{* P G c}(\theta)=(\alpha+\beta) \ln \left[(1-\tau-\theta)+R^{-1} n \tau \bar{h}_{t+1} / \bar{h}_{t}\right]+\gamma(1-\sigma) \ln \theta+D_{1} \\
& U_{t}^{* P G f}(\omega, \theta)=(\alpha+\beta) \ln \left[(1-\tau-\theta) h_{t}(\omega)+R^{-1} n \tau \bar{h}_{t+1}\right]+\gamma(1-\sigma) \ln \theta+D_{2}
\end{aligned}
$$

where $D_{1}$ and $D_{2}$ summarize the terms in the respective expressions that do not depend on $\theta$.

Since, according to Lemma 1, both value functions are strictly concave the first order conditions of their maxima uniquely determine the respective individually preferred levels of the education tax rate.

In particular, note that under the PAYG system with contribution related benefits preferences are unanimous since the value function (16) is invariant across contemporary individuals. We differentiate (16) using the expression (10) and after straightforward algebraic transformation we obtain

$$
\begin{array}{r}
\frac{\partial U_{t}^{* P G c}(\theta)}{\partial \theta}=d_{1}\left\{(1-\sigma)(\alpha+\beta+\gamma) B R^{-1} w^{1-\sigma} n^{\sigma} \tau \theta^{1-\sigma} M_{t}+\right. \\
+\gamma(1-\sigma)(1-\tau)-\theta[\alpha+\beta+\gamma(1-\sigma)]\}
\end{array}
$$

where $d_{1}$ is an expression which is positive for any value of the tax rate $\theta$. Therefore the DPE tax rate $\theta_{t}^{P G c}$ is defined by the first order condition

$$
(1-\sigma)(\alpha+\beta+\gamma) B R^{-1} w^{1-\sigma} n^{\sigma} \tau \theta^{1-\sigma} M_{t}+\gamma(1-\sigma)(1-\tau)-\theta[\alpha+\beta+\gamma(1-\sigma)]=0
$$

Furthermore, thanks to strict concavity of the value function (16), based on the sign of the derivative $\left.\frac{\partial U_{t}^{* P G c}(\theta)}{\partial \theta}\right|_{\theta=\theta^{F F c}}$ one can infer the relationship between $\theta_{t}^{P G c}$ and the DPE tax rate $\theta^{F F c}$ given by formula (14a), which corresponds to the fully funded contribution related pension benefit scheme. Thus we substitute $\theta=\theta^{F F c}$ in the expression (18) and verify its sign. This along with formula (15) yields the following result: 
Proposition 2: For a given social security tax rate $t$ and the contribution related retirement benefit formula, the PAYG pension scheme (11c) will result in higher DPE education tax rate and per capita growth factor than the FF system (11a), i.e. the following inequalities:

$$
\theta_{t}^{P G c}>\theta^{F F c} \text { and } g_{t}^{P G c}>g_{t}^{F F c}
$$

are true in a period $t=0,1, \ldots$, if and only if the following condition holds:

$$
B R^{-1} w^{1-\sigma} n^{\sigma}\left[\frac{\gamma(1-\sigma)}{\alpha+\beta+\gamma(1-\sigma)}\right]^{1-\sigma} M_{t}>\frac{\gamma}{\alpha+\beta+\gamma}
$$

where $M_{t}$ is the expression defined in (10).

We now apply a similar analysis to the case of PAYG system with flat benefit formula. Differentiating the individual value function (17) we obtain, after straightforward algebraic transformations and using the relationship (10):

$$
\begin{array}{r}
\frac{\partial U_{t}^{* P G f}(\theta, \omega)}{\partial \theta}=d_{2}\left\{(1-\sigma)(\alpha+\beta+\gamma) B R^{-1} w^{1-\sigma} n^{\sigma} \tau \theta^{1-\sigma} M_{t} \frac{\bar{h}_{t}}{h_{t}(\omega)}+\right. \\
+\gamma(1-\sigma)(1-\tau)-\theta[\alpha+\beta+\gamma(1-\sigma)]\}
\end{array}
$$

where $d_{2}$ is an expression which is positive for any value of the tax rate $\theta$. We now substitute the value $\theta=\theta_{t}^{F F f}$ given by formula (14b) in the expression (20) and obtain

$$
\begin{aligned}
& \left.\frac{\partial U_{t}^{* P G f}(\theta)}{\partial \theta}\right|_{\theta=\theta_{t}^{F F f}}= \\
& =d_{3}\left\{(\alpha+\beta+\gamma) B R^{-1} w^{1-\sigma} n^{\sigma}\left[\frac{\gamma(1-\sigma)}{\alpha+\beta+\gamma(1-\sigma)}\right]^{1-\sigma}\left[1-\tau+\tau \frac{\bar{h}_{t}}{h_{t}(\omega)}\right]^{1-\sigma} M_{t}-\gamma\right\}
\end{aligned}
$$

where $d_{3}$ is an expression positive for any $\theta$.

While expressions (20) and (21) are individual-specific, note that they are strictly decreasing in individual human capital attainment $h_{t}(\omega)$. Therefore under majority voting the DPE outcomes for generation $\mathrm{t}$ will be determined by the median voter's human capital attainment, which we denote by $h_{t}^{\text {med }}$. Then similarly to the above analysis we 
need to examine the sign of expression (21) for $h_{t}(\omega)=h_{t}^{\text {med }}$ in order to determine the relationship between the DPE education tax rates $\theta_{t}^{F F f}$ and $\theta_{t}^{P G f}$ under the respective flat benefit social security systems. This analysis yields the following result:

Proposition 3: For a given pension contribution rate $t$ and the flat retirement benefit formula, the PAYG pension scheme (11d) will result in higher DPE education tax rate and per capita growth factor than the FF system (11b), i.e. the following inequalities:

$$
\theta_{t}^{\text {PGf }}>\theta_{t}^{\text {FFf }} \text { and } g_{t}^{\text {PGf }}>g_{t}^{\text {FFf }}
$$

are true in period $t$, if and only if the following condition holds:

$$
B R^{-1} w^{1-\sigma} n^{\sigma}\left[\frac{\gamma(1-\sigma)}{\alpha+\beta+\gamma(1-\sigma)}\right]^{1-\sigma}\left[1-\tau+\tau \frac{\bar{h}_{t}}{h_{t}^{\text {med }}}\right]^{1-\sigma} M_{t}>\frac{\gamma}{\alpha+\beta+\gamma}
$$

Discussion. According to the equation (10) and formulas (14a) and (14b) the left-hand sides of inequalities in (19) and (22) are equal to $\frac{n \bar{h}_{t+1}}{R \bar{h}_{t}}$, the real growth factor of the economy's human capital in a DPE under the fully funded pension scheme, with contribution related benefits in the case of inequality (19) and flat benefits in the case of (22). The right-hand side in both (19) and (22) represents the degree of each individual's altruistic concern for the human capital attainment of his children. It is not difficult to see therefore that under the Cobb-Douglas specifications of our model, the inequalities in (19) or (22) compare the altruistic return on investment in education, which is its only motive under an FF pension system, to the marginal economic return in terms of pension benefits under a PAYG scheme on additional investment in education, beyond the tax rate prescribed by the respective FF system $\left(\theta^{F F c}\right.$ or $\theta_{t}^{F F f}$ respectively). Indeed, a PAYG scheme brings about an additional non-altruistic motive to finance public education since it increases wage incomes in the next generation, of which the retirees will receive a share under PAYG scheme. Specifically, if the inequality (19) is satisfied, the return to future retirees generated by such additional education funding under the PAYG system is high enough; hence the result of Proposition 2 that the PAYG system would yield a relatively higher education tax rate than the respective FF system, thus $\theta_{t}^{P G c}>\theta^{F F c}$. This result may be overturned, however, when inequality (19) is violated because the preferred tax based on the altruistic motive declines if the move to a PAYG scheme reduces lifetime income when the rate of return on social security contributions falls short of the interest rate. 
As pointed out in Section 2 following the equation (10), the value of expression $M_{t}$ is at most 1 , which obtains only if human capital levels are identical across contemporary individuals, and furthermore $M_{t}$ declines with increasing dispersion of incomes/human capital levels. Thus conditions in (19) and (22) impose a bound on the degree of income inequality.

Propositions 2 and 3 show in particular, according to the conditions (19) and (22), that the scenario where DPE education tax rate and the growth rate of per capita GDP will be higher under a PAYG scheme than under the respective funded system is likely in an environment with some of the following features: moderate degree of inequality, strong public education system ( $B$ is relatively large), the wage income of a median voter is below the economy's average and a culture where parents give relatively low priority to the human capital attainment of their children (? relatively small).

We note that the conditions listed above are characteristic of developed economies. We also remark that when the median voter's wage is below the economy's average, the inequality (19) automatically implies (22).

Combining the results of Propositions 2 and 3 with those of Proposition 1(i) and Theorem 1(i) we obtain the main result of this section:

Theorem 2: Consider the DPE outcomes in otherwise identical four small open economies, where condition (19) is satisfied and median voter's wage is below the economy's average, but which use different alternative pension schemes defined by the formulae (11a)-(11d) with the same pension contribution rate $t$ at $t=0,1, \ldots$. The economy using the PAYG social security system with flat benefit pension formula (PGf) delivers the highest DPE education tax rates and per capita growth rates.

We can thus conclude that under the conditions characteristic of (small open) developed economies the PAYG flat benefit social security system, i.e. the one most redistributive both between and within generations is most conducive, relative to the alternatives systems given the same contribution rate, of public investment in human capital and hence economic growth. As we explained earlier, the role of intergenerationally redistributive feature of the PAYG system is that it provides an economic incentive to fund the next generation's education, through the link between the retiree pension benefits and their 
contemporary workers' productivity. The pension formula which is progressively redistributive among the retirees enhances the majority's support for higher rates of education taxes, provided that the electorate's income distribution is right-skewed.

An essential assumption in Theorem 2 is that the median voter is a worker earning a below average wage, which makes Theorem 1(i) applicable. If instead the median voter's wage was above the average, then Theorem 1(ii) would apply, and combining it with Propositions 2 and 3 one would obtain, given that both (19) and (22) remained satisfied, that it is the contribution-related PAYG scheme that delivers the highest education tax and the fastest growth. Although wage distributions are typically right-skewed, note that as argued in the Discussion at the end of Section 3, under a public finance system where retirees are also subject to the education tax, they would be in opposition to it, so the median voter on the issue would likely be a worker earning more than the average wage.

The above results on the effects of pension schemes on education funding and growth raise a question whether they are associated with technological inefficiencies in resource allocations. In this event, output growth is not at its maximum for given levels of aggregate investment in human and physical capital. We note that an intertemporal allocation of resources to human capital investment is not efficient if $\frac{\partial \bar{h}_{t+1}}{\partial e_{t}} w>R$ holds at the margin. Indeed, when the marginal product of public education exceeds that of physical capital, an intergenerational Pareto improvement can be achieved by investing more in public education rather than in physical capital, where the government debt can be repaid by taxing the active generation in the next period. If such a scenario occurs, an obvious question is why the government does not pursue the policy of greater funding of education anyway. In the real world economies, the government institutions responsible for funding public education face hard fiscal constraints, including the caps on borrowing. Besides, in many countries education funding is provided at a regional or even local level making it difficult to capture the productivity gains resulting from jurisdiction specific education investment.

The level of education funding is technologically efficient for a particular student if $\frac{\partial h_{t+1}(\omega)}{\partial e_{t}} w=R$ is true. If contracts with minors could be enforced, parents would simply transfer the necessary amount to finance the efficient level of education. The children would repay their debt with interest in the next period. Altruistic parents could then 
make some additional transfer in the form of physical capital or the final good, either inter vivos or as a bequest. Therefore, if parents are indifferent between giving the same amount of money as education funding or in cash, overinvestment in education can occur only if the pension scheme redistributes toward the median voter. Since the altruistic motive may well be too weak to ensure a sufficiently high level of public education, the PAYG scheme can act as a device to enhance welfare by promoting investment in human capital.

\section{The choice of a pension scheme}

The results of the previous section show that for a wide range of parameters characteristic of developed economies a PAYG pension scheme tends to generate support for higher public funding of education than a comparable FF system would. The above results characterize a comparison of otherwise identical four open economies where the alternative social security systems ( $F F c, F F f, P G c, P G f)$ are in place and are not themselves subject to public choice. In order to approach the latter issue, we need to compare these alternative pension systems in terms of rates of return they generate for the ir constituents. The clear benchmark for this comparison is the FF system with contribution related benefit formula (11a) which provides each retiree the benefit return on his contributions equal to the return on private savings under the interest factor $R$.

Let $\rho_{t}^{S}(\omega)$ be the rate of return a pension system $\mathrm{S}$ (i.e., one of the four alternative arrangements $F F c$, $F F f, P G c, P G f$ under consideration) provides for generation $t$ individual in family $\omega$ on his contributions into the system. As mentioned above,

$$
\rho_{t}^{F F c}(\omega) \equiv R
$$

Therefore, according to (11b),

$$
\rho_{t}^{F F f}(\omega)=\frac{\bar{h}_{t}}{h_{t}(\omega)} R
$$

and thereby the median voter's return to his social security contributions is given by

$$
\rho_{t}^{F F f}\left(\omega^{\text {med }}\right)=\frac{\bar{h}_{t}}{h_{t}^{\text {med }}} R
$$

Further, according to formulae (11c) and (10) the PAYG system with contribution related benefit formula provides each individual in generation $t$ the rate of return

$$
\rho_{t}^{P G c}(\omega) \equiv \rho_{t}^{P G c}=\frac{n \bar{h}_{t+1}}{\bar{h}_{t}}=B w^{1-\sigma} n^{\sigma}\left(\theta_{t}^{P G c}\right)^{1-\sigma} M_{t}
$$


on his social security contributions, where as before $\theta_{t}^{P G c}$ stands for the DPE education tax rate chosen by generation $\mathrm{t}$ if this pension system is in place.

The education tax rate $\hat{\theta}$ that induces the rate of return on social security contributions under a contribution-related PAYG scheme to become equal to the interest factor $R$ is

$$
\hat{\theta}=w^{-1}\left[\frac{R}{B n^{\sigma} M_{t}}\right]^{\frac{1}{1-\sigma}}
$$

Similarly, according to (11d) and (10), the rate of such return for a generation $t$ individual in family $\omega$ under PAYG system with this redistributive flat benefit formula will be

$$
\rho_{t}^{P G f}(\omega)=\frac{n \bar{h}_{t+1}}{h_{t}(\omega)}=\frac{\bar{h}_{t}}{h_{t}(\omega)} B w^{1-\sigma} n^{\sigma}\left(\theta_{t}^{P G f}\right)^{1-\sigma} M_{t}
$$

We will first focus on the comparison of this rate of return to the return on private savings, i.e. the interest factor $R$. According to (27) for these factors to be equal the education tax rate $\theta$ chosen under the $P G f$ pension system would have to satisfy the equation

$$
\frac{\bar{h}_{t}}{h_{t}(\omega)} B w^{1-\sigma} n^{\sigma} \theta^{1-\sigma} M_{t}=R
$$

i.e. to be equal to

$$
\bar{\theta}(\omega)=w^{-1}\left[\frac{h_{t}(\omega)}{\bar{h}_{t}} \frac{R}{B n^{\sigma} M_{t}}\right]^{\frac{1}{1-\sigma}}
$$

Since according to (27) the rate of return on pension benefits is an increasing function of the education tax rate $\theta$, the comparison of $\rho_{t}^{P G f}(\omega)$ to $R$ is equivalent to that of $\theta_{t}^{P G f}(\omega)$ to $\bar{\theta}(\omega)$. The result of the latter comparison is obtained similarly to our proof of Proposition 3, ie. by substituting $\theta=\bar{\theta}(\omega)$ into the formula (20) of the marginal value $\frac{\partial U_{t}^{* P G f}(\theta, \omega)}{\partial \theta}$ and verifying its sign. Namely, due to strict concavity of the value function the inequality $\theta_{t}^{P G f}(\omega)<\bar{\theta}(\omega)$ is equivalent to $\frac{\partial U_{t}^{* P G f}(\bar{\theta}, \omega)}{\partial \theta}<0$. A straightforward application of this analysis to the median voter and proceeding analogously for the contribution-related-formulas yields the following results. 
Proposition 4: (i) The inequality $\theta_{t}^{P G f}<\bar{\theta}\left(\omega^{\text {med }}\right)$ and equivalently $\rho_{t}^{P G f}\left(\omega^{\text {med }}\right)<R$ are true, i.e. the median voter's return on pension contributions under PAYG flat benefit social security system falls short of the return on private savings, iff the following condition holds:

$$
B R^{-1} w^{1-\sigma} n^{\sigma} \frac{\overline{h_{t}}}{h_{t}^{\text {med }}}\left[\frac{\gamma(1-\sigma)}{\alpha+\beta+\gamma(1-\sigma)}\right]^{1-\sigma}\left[1-\tau+\tau \frac{\alpha+\beta+\gamma}{\gamma}\right]^{1-\sigma} M_{t}<1
$$

(ii) The inequality $\theta_{t}^{P G c}<\hat{\theta}$ and equivalently $\rho_{t}^{P G c}<R$ are true, i.e. the return under $P A Y G$ contribution-related social security systems falls short of the return on private savings, iff the following condition holds:

$$
B R^{-1} w^{1-\sigma} n^{\sigma}\left[\frac{\gamma(1-\sigma)}{\alpha+\beta+\gamma(1-\sigma)}\right]^{1-\sigma}\left[1-\tau+\tau \frac{\alpha+\beta+\gamma}{\gamma}\right]^{1-\sigma} M_{t}<1
$$

It can be easily seen that inequalities (30a) and (30b) are broadly consistent with the conditions (19) and (22), i.e. both sets of conditions are satisfied for a wide subset of the range of parameters. Specifically, (30a) and (30b) impose reasonable upper bounds on fertility $n$, the productivity parameter $B$ of the public education system, as well as skewness of wage distribution in the electorate $\frac{\bar{h}_{t}}{h_{t}^{\text {med }}}$.

Recall that according to Theorem 2, if condition (19) is satisfied, then growth will be the fastest under the $P G f$ pension formula. Therefore, noting that when the distribution of wages is right-skewed redistributive pension formulas are preferred to the contribution-related formulas by a majority of voters, we confine our attention to the choice between pension schemes with a redistributive (flat) benefit formula. We now couple the result of Proposition 4 with that of Proposition 1(i) and based on formulas (23)-(25) and (27) obtain the following:

Theorem 3: Consider a small open economy which satisfies the parametric conditions (19), (22) and (30a). Assume that a pension scheme is to be chosen in period $t$ among the alternatives defined by the formulae (11a)-(11d) with a given pension contribution rate $t$, and that the corresponding DPE education tax rate is determined accordingly (as described by (14a)-(14d)). Then the corresponding rates of return to pension contributions of a median worker in generation $t$ will compare as follows: 


$$
\rho_{t}^{F F f}\left(\omega^{\text {med }}\right)>\rho_{t}^{F F c} \equiv R>\rho_{t}^{\text {PGf }}\left(\omega^{\text {med }}\right)>\rho_{t}^{\text {PGc }}
$$

regardless of what pension system, if any, was in place prior to period $t$.

Since according to (31) the return to social security contributions is higher under the funded scheme, then other things equal including the same level of education tax rate, the welfare level of every working age individual will be higher under a fully funded than under the corresponding PAYG scheme. Propositions 2 and 3 state, furthermore, that the majority of young agents will choose lower education tax rates under fully funded schemes. Thus this revealed preference argument proves the following:

Corollary: Under the provisions of Theorem 3 a majority of young voters in each generation $t$ will prefer a fully funded system over a PAYG arrangement.

It is obvious, however, that retirees in each period will be unequivocally in favor of a PAYG arrangement. ${ }^{4}$ Even if there are fewer old people in the economy than those in the working age, the median voter in the combined electorate on the issue of choosing a social security system will be, as also pointed out by Conde-Ruiz and Galasso (2005), a low income young agent, such that the inequality (30a) can be violated. ${ }^{5}$ In this likely scenario the PGf social security system will be sustained despite the wishes of the majority of the working population. The important implication of our results stemming from Theorem 2 is that this scenario is characterized by consistently higher rates of economic growth.

Therefore, while according to the Corollary the majority of young agents always prefer to deviate from the $P G f$ social security system based on their lifetime welfare maximization, this individually rational incentive ignores the benefit these agents have received from the past higher growth rates due in part to the PAYG system which was in place in prior periods. It similarly ignores the longer-term benefits of economic growth for the future generations, if the PAYG system is sustained.

\footnotetext{
${ }^{4}$ In a more realistic OLG framework with multiple coexisting age cohorts older cohorts of workers would join the retirees in their support of a PAYG scheme (see e.g. Browning, 1975).
} 
We can thus conclude: While the intergenerational transfer system with PGf pension scheme is sustained due to the support of all of the old and a minority of the young, it causes a majority of the young to support higher public funding of education and thereby ensures the overall highest long-term growth.

\section{Conclusions}

This paper challenges the common concern that PAYG schemes harm growth This is believed to be the case due to the negative effect of PAYG systems on physical capital formation. We abstract away from this concern by considering the case of a small open economy with open capital markets and focus instead on the effect of pension systems on human capital accumulation. We consider an economy where human capital accumulation is publicly financed, which seems to be a valid description of the situation in most OECD countries. We show, using a political economy framework, that the introduction of PAYG pension schemes can have a positive effect on economic growth. The reason is that a majority of voters will support higher taxes tor finance public education today when they can expect to receive higher PAYG pensions tomorrow in return. In this way, PAYG pension scheme can serve as a device to overcome a tendency toward underinvestment in public education.

Furthermore, an intra-generationally redistributive PAYG scheme (for example the one where benefits are flat rather than contribution related) may lead to an even faster growth. Indeed, investment in public education will be higher if the median voter benefits from redistribution in PAYG pension benefits. One should, however, balance this against a counteracting effect of a labor supply response to the redistributive policy.

An obvious alternative to our framework would be a specification in which public education can be supplemented by private education, as a perfect substitute. In such a framework, the preferred education tax of all individuals with more than average income would be zero when a funded pension scheme is in place. Should the preferred education tax of poorer voters rise with increasing income, an ends-against-the-middle coalition may be formed as in Epple and Romano (1996), where the median voter has less than the median wage. Although some private schooling is crowded out by increas-

\footnotetext{
${ }^{5}$ When voters choose the rate of contribution to a redistributive scheme, the winning coalition often consists of retirees and workers with medium wages, who prefer higher contribution rates than rich or poor workers (Casamatta et al., 2000).
} 
ing public schooling in such a mixed education regime, the tendency of a positive impact of extending PAYG schemes on aggregate investment in education will continue to hold.

The main caveat of our analysis obviously lies in the assumption that the choice of a pension system has no effect on the level of physical capital in a small open economy. It is important to point out, however, that even if each economy under consideration is small compared to the rest of the world, a symmetric choice of pension policies in all countries, which may be favorable to growth from the perspective of each individual country, can under certain conditions have a negative impact on global physical capital formation. 


\section{Appendix}

\section{Proof of Lemma 1.}

Differentiating the value function with respect to $\theta$ yields

$$
\frac{\partial U^{*}}{\partial \theta}=(\alpha+\beta) \frac{\frac{1}{R} \frac{\partial \pi_{i t+1}}{\partial \theta}-w_{i t}}{(1-\tau-\theta) w_{i t}+\frac{\pi_{i t+1}}{R}}+\frac{\gamma(1-\sigma)}{\theta}
$$

Since $\frac{\gamma(1-\sigma)}{\theta}$ is decreasing in $\theta$, it suffices to show that $V(\theta)=\frac{\frac{1}{R} \frac{\partial \pi_{i t+1}}{\partial \theta}-w_{i t}}{(1-\tau-\theta) w_{i t}+\frac{\pi_{i t+1}}{R}}$ also falls with rising $\theta$. It turns out that

$\operatorname{sgn}\left[\frac{\partial V(\theta)}{\partial \theta}\right]=\operatorname{sgn}\left[\frac{1}{R} \frac{\partial^{2} \pi_{i t+1}}{\partial \theta^{2}}\left[(1-\tau-\theta) w_{i t}+\frac{\pi_{i t+1}}{R}\right]-\left[\frac{1}{R} \frac{\partial \pi_{i t+1}}{\partial \theta}-w_{i t}\right]^{2}\right]$

Thus, it is enough to establish that $\frac{\partial^{2} \pi_{i t+1}}{\partial \theta^{2}} \leq 0$. Under any funded scheme we have $\frac{\partial \pi_{i t+1}}{\partial \theta}=0$ for any $\theta$, while under any PAYG scheme $\frac{\partial^{2} \pi_{i t+1}}{\partial \theta^{2}}<0$ holds. 


\section{References}

Becker, G. S. and K. M. Murphy (1988) The family and the state. Journal of Law and Economics 31, 1-18.

Boldrin, M. (2005) Public education and capital accumulation. Research in Economics 59, 85-109.

Boldrin, M. and A. Montes. (2005) The intergenerational state: education and pensions. Review of Economic Studies 62, 651-664.

Browning, E K. (1975) Why the social insurance budget is too large in a democracy. Economic Inquiry 13, 373-388.

Casamatta, G., H. Cremer and P. Pestieau (2000) The political economy of social security. Scandinavian Journal of Economics 102, 503-522.

Conde-Ruiz J. I. and V. Galasso (2005) Positive arithmetic of the welfare state. Journal of Public Economics 89, 933-955.

Docquier, F. and O. Paddison (2003) Social security benefit rules, growth and inequality. Journal of Macroeconomics 25, 47-71.

Epple, D. and R. Romano (1996) Ends against the middle: determining public service provision when there are private alternatives. Journal of Public Economics 62, 297-325.

Feldstein, M. (1974) Social security, induced retirement and aggregate capital accumulation. Journal of Political Economy 82, 905-926.

Glomm, G. and M. Kaganovich (2008) Social security, public education and the growth-inequality relationship. European Economic Review 52, 1009-1034.

Gradstein, M., M. Justman and V. Meier (2005) The political economy of education, MIT Press: Cambridge MA and London.

Gradstein, M. and M. Kaganovich (2004) Aging population and education finance. Journal of Public Economics 88, 2469-2485. 
Holtz-Eakin, D., M. E. Lovely and M. S. Tosun (2004) Generational conflict, fiscal policy, and economic growth. Journal of Macroeconomics 26, 1-23.

Kaganovich, M. and I. Zilcha (1999) Education, social security and growth. Journal of Public Economics 71, 289-309.

Kaganovich, M. and I. Zilcha (2008) Alternative pension systems and growth. CESifo Working Paper No. 2353, Munich.

Kemnitz, A. (2000) Social security, public education, and growth in a representative democracy. Journal of Population Economics 13, 443-462.

Kemnitz, A. and B. U. Wigger (2000) Growth and social security: the role of human capital. European Journal of Political Economy 16, 673-683.

Konrad, K. (1995) Social security and strategic inter-vivos transfers of social capital. Journal of Population Economics 8, 315-326.

Lambrecht, S., P. Michel and J.-P. Vidal (2005) Public pensions and growth. European Economic Review 49, 1261-1281.

Pecchenino, R. A. and K. R. Utendorf (1999) Social security, social welfare and the aging population. Journal of Population Economics 12, 607-623.

Pogue, T. F. and L. G. Sgontz (1977) Social security and investment in human capital. National Tax Journal 30, 157-169.

Poterba, J. M. (1997) Demographic structure and the political economy of public education. Journal of Policy Analysis and Management 16, 48-66.

Poterba, J. M. (1998) Demographic change, intergenerational linkages, and public education. American Economic Review, Papers and Proceedings 88, 315-320.

Poutvaara, P. (2006) On the political economy of social security and public education. Journal of Population Economics 19, 345-365.

Rangel, A. (2003) Forward and backward intergenerational goods: why is social security good for the environment? American Economic Review 93, 813-834. 
Sinn, H.-W. (2004) The pay-as-you-go system as a fertility insurance and enforcement device. Journal of Public Economics 88, 1335-1357.

Soares, J. (2006) A dynamic general equilibrium analysis of the political economy of public education. Journal of Population Economics 19, 367-389. 


\section{CESifo Working Paper Series}

for full list see www.cesifo-group.org/wp

(address: Poschingerstr. 5, 81679 Munich, Germany, office@cesifo.de)

2425 Bruno S. Frey, David A. Savage and Benno Torgler, Noblesse Oblige? Determinants of Survival in a Life and Death Situation, October 2008

2426 Giovanni Facchini, Peri Silva and Gerald Willmann, The Customs Union Issue: Why do we Observe so few of them?, October 2008

2427 Wido Geis, Silke Uebelmesser and Martin Werding, Why go to France or Germany, if you could as well go to the UK or the US? Selective Features of Immigration to four major OECD Countries, October 2008

2428 Geeta Kingdon and Francis Teal, Teacher Unions, Teacher Pay and Student Performance in India: A Pupil Fixed Effects Approach, October 2008

2429 Andreas Haufler and Marco Runkel, Firms' Financial Choices and Thin Capitalization Rules under Corporate Tax Competition, October 2008

2430 Matz Dahlberg, Heléne Lundqvist and Eva Mörk, Intergovernmental Grants and Bureaucratic Power, October 2008

2431 Alfons J. Weichenrieder and Tina Klautke, Taxes and the Efficiency Costs of Capital Distortions, October 2008

2432 Andreas Knabe and Ronnie Schöb, Minimum Wage Incidence: The Case for Germany, October 2008

2433 Kurt R. Brekke and Odd Rune Straume, Pharmaceutical Patents: Incentives for R\&D or Marketing?, October 2008

2434 Scott Alan Carson, Geography, Insolation, and Institutional Change in $19^{\text {th }}$ Century African-American and White Stature in Southern States, October 2008

2435 Emilia Del Bono and Daniela Vuri, Job Mobility and the Gender Wage Gap in Italy, October 2008

2436 Marco Angrisani, Antonio Guarino, Steffen Huck and Nathan Larson, No-Trade in the Laboratory, October 2008

2437 Josse Delfgaauw and Robert Dur, Managerial Talent, Motivation, and Self-Selection into Public Management, October 2008

2438 Christian Bauer and Wolfgang Buchholz, How Changing Prudence and Risk Aversion Affect Optimal Saving, October 2008

2439 Erich Battistin, Clara Graziano and Bruno Parigi, Connections and Performance in Bankers' Turnover: Better Wed over the Mixen than over the Moor, October 2008 
2440 Erkki Koskela and Panu Poutvaara, Flexible Outsourcing and the Impacts of Labour Taxation in European Welfare States, October 2008

2441 Marcelo Resende, Concentration and Market Size: Lower Bound Estimates for the Brazilian Industry, October 2008

2442 Giandomenico Piluso and Roberto Ricciuti, Fiscal Policy and the Banking System in Italy. Have Taxes, Public Spending and Banks been Procyclical in the Long-Run? October 2008

2443 Bruno S. Frey and Katja Rost, Do Rankings Reflect Research Quality?, October 2008

2444 Guglielmo Maria Caporale, Antoaneta Serguieva and Hao Wu, Financial Contagion: Evolutionary Optimisation of a Multinational Agent-Based Model, October 2008

2445 Valentina Bosetti, Carlo Carraro and Massimo Tavoni, Delayed Participation of Developing Countries to Climate Agreements: Should Action in the EU and US be Postponed?, October 2008

2446 Alexander Kovalenkov and Xavier Vives, Competitive Rational Expectations Equilibria without Apology, November 2008

2447 Thiess Buettner and Fédéric Holm-Hadulla, Cities in Fiscal Equalization, November 2008

2448 Harry H. Kelejian and Ingmar R. Prucha, Specification and Estimation of Spatial Autoregressive Models with Autoregressive and Heteroskedastic Disturbances, November 2008

2449 Jan Bouckaert, Hans Degryse and Thomas Provoost, Enhancing Market Power by Reducing Switching Costs, November 2008

2450 Frank Heinemann, Escaping from a Combination of Liquidity Trap and Credit Crunch, November 2008

2451 Dan Anderberg, Optimal Policy and the Risk Properties of Human Capital Reconsidered, November 2008

2452 Christian Keuschnigg and Evelyn Ribi, Outsourcing, Unemployment and Welfare Policy, November 2008

2453 Bernd Theilen, Market Competition and Lower Tier Incentives, November 2008

2454 Ondřej Schneider, Voting in the European Union - Central Europe's Lost Voice, November 2008

2455 Oliver Lorz and Gerald Willmann, Enlargement versus Deepening: The Trade-off Facing Economic Unions, November 2008 
2456 Alfons J. Weichenrieder and Helen Windischbauer, Thin-Capitalization Rules and Company Responses, Experience from German Legislation, November 2008

2457 Andreas Knabe and Steffen Rätzel, Scarring or Scaring? The Psychological Impact of Past Unemployment and Future Unemployment Risk, November 2008

2458 John Whalley and Sean Walsh, Bringing the Copenhagen Global Climate Change Negotiations to Conclusion, November 2008

2459 Daniel Mejía, The War on Illegal Drugs in Producer and Consumer Countries: A Simple Analytical Framework, November 2008

2460 Carola Frydman, Learning from the Past: Trends in Executive Compensation over the Twentieth Century, November 2008

2461 Wolfgang Ochel, The Political Economy of Two-tier Reforms of Employment Protection in Europe, November 2008

2462 Peter Egger and Doina Maria Radulescu, The Influence of Labor Taxes on the Migration of Skilled Workers, November 2008

2463 Oliver Falck, Stephan Heblich and Stefan Kipar, The Extension of Clusters: Differencein-Differences Evidence from the Bavarian State-Wide Cluster Policy, November 2008

2464 Lei Yang and Keith E. Maskus, Intellectual Property Rights, Technology Transfer and Exports in Developing Countries, November 2008

2465 Claudia M. Buch, The Great Risk Shift? Income Volatility in an International Perspective, November 2008

2466 Walter H. Fisher and Ben J. Heijdra, Growth and the Ageing Joneses, November 2008

2467 Louis Eeckhoudt, Harris Schlesinger and Ilia Tsetlin, Apportioning of Risks via Stochastic Dominance, November 2008

2468 Elin Halvorsen and Thor O. Thoresen, Parents' Desire to Make Equal Inter Vivos Transfers, November 2008

2469 Anna Montén and Marcel Thum, Ageing Municipalities, Gerontocracy and Fiscal Competition, November 2008

2470 Volker Meier and Matthias Wrede, Reducing the Excess Burden of Subsidizing the Stork: Joint Taxation, Individual Taxation, and Family Splitting, November 2008

2471 Gunther Schnabl and Christina Ziegler, Exchange Rate Regime and Wage Determination in Central and Eastern Europe, November 2008

2472 Kjell Erik Lommerud and Odd Rune Straume, Employment Protection versus Flexicurity: On Technology Adoption in Unionised Firms, November 2008 
2473 Lukas Menkhoff, High-Frequency Analysis of Foreign Exchange Interventions: What do we learn?, November 2008

2474 Steven Poelhekke and Frederick van der Ploeg, Growth, Foreign Direct Investment and Urban Concentrations: Unbundling Spatial Lags, November 2008

2475 Helge Berger and Volker Nitsch, Gotcha! A Profile of Smuggling in International Trade, November 2008

2476 Robert Dur and Joeri Sol, Social Interaction, Co-Worker Altruism, and Incentives, November 2008

2477 Gaëtan Nicodème, Corporate Income Tax and Economic Distortions, November 2008

2478 Martin Jacob, Rainer Niemann and Martin Weiss, The Rich Demystified - A Reply to Bach, Corneo, and Steiner (2008), November 2008

2479 Scott Alan Carson, Demographic, Residential, and Socioeconomic Effects on the Distribution of $19^{\text {th }}$ Century African-American Stature, November 2008

2480 Burkhard Heer and Andreas Irmen, Population, Pensions, and Endogenous Economic Growth, November 2008

2481 Thomas Aronsson and Erkki Koskela, Optimal Redistributive Taxation and Provision of Public Input Goods in an Economy with Outsourcing and Unemployment, December 2008

2482 Stanley L. Winer, George Tridimas and Walter Hettich, Social Welfare and Coercion in Public Finance, December 2008

2483 Bruno S. Frey and Benno Torgler, Politicians: Be Killed or Survive, December 2008

2484 Thiess Buettner, Nadine Riedel and Marco Runkel, Strategic Consolidation under Formula Apportionment, December 2008

2485 Irani Arraiz, David M. Drukker, Harry H. Kelejian and Ingmar R. Prucha, A Spatial Cliff-Ord-type Model with Heteroskedastic Innovations: Small and Large Sample Results, December 2008

2486 Oliver Falck, Michael Fritsch and Stephan Heblich, The Apple doesn't Fall far from the Tree: Location of Start-Ups Relative to Incumbents, December 2008

2487 Cary Deck and Harris Schlesinger, Exploring Higher-Order Risk Effects, December 2008

2488 Michael Kaganovich and Volker Meier, Social Security Systems, Human Capital, and Growth in a Small Open Economy, December 2008 